\title{
Saúde do trabalhador em educação: a gestão da saúde de professores de escolas públicas brasileiras'
}

\section{Occupational health education: health management of Brazilian public school teachers}

\author{
Franciele Ariene Lopes Santana \\ Universidade Federal de Mato Grosso do Sul. Programa de \\ Pós-Graduação em Educação Social. Corumbá, MS, Brasil. \\ E-mail: franciele.santanaळufms.br

\section{Ilidio Roda Neves} \\ Universidade Federal de Mato Grosso do Sul. Programa de \\ Pós-Graduação em Educação Social. Corumbá, MS, Brasil. \\ E-mail: ilidio.nevesळufms.br
}

\section{Resumo}

A saúde docente tem, ao longo dos últimos anos, chamado a atenção da academia para o sofrimento e o mal-estar decorrentes do trabalho e, para nós, para a forma como o poder público tem atuado sobre tal realidade. 0 objetivo deste estudo foi compreender, por meio de uma revisão da literatura, "se" e "como" a gestão em saúde do trabalhador tem proposto ações e políticas para os docentes. 0 caminho metodológico foi a revisão integrativa de literatura. Foram encontradas 242 publicações; destas, 52 foram selecionadas para leitura na íntegra, contudo apenas quatro apontam assistência por meio da gestão em Saúde Pública. Perante esta realidade, levantamos três hipóteses: os programas voltados para esta categoria estão sendo realizados, mas as experiências não são divulgadas; as instituições de pesquisa não têm se interessado pelo tema; ou ainda: realmente não existem programas que trabalhem com adoecimento docente no âmbito das políticas públicas. Concluímos que são necessárias ações e políticas que não silenciem a realidade, bem como novos estudos tanto do processo saúde/adoecimento como da falta de gestão sobre ele.

Palavras-chave: Saúde do Trabalhador; Adoecimento; Docente; Gestão da Saúde.

\section{Corrrespondência}

Franciele Ariene Lopes Santana

Alameda Catarina da Cunha, 127, Dom Bosco. Corumbá, MS, Brasil.

CEP 79333-10I.

1 Este estudo fez parte da pesquisa desenvolvida junto ao programa de Pós-Graduação em Gestão em Saúde, da Universidade Estadual de Mato Grosso do Sul (UEMS). Não houve financiamento. 


\section{Abstract}

Over the past few years, teachers' health has been drawing attention of university studies, especially regarding work-related disorders and, for us, the way the government has acted on this particular reality. This paper aimed to understand, by means of an integrative literature review, "if" and "how" workers' health management has proposed actions and policies for teachers. We accessed the Virtual Health Library to survey data from 1990 to 2014. From the 242 publications found, 52 were analyzed. Only four publications registered assistance via Public Health Management. Towards this reality, we raised three hypotheses: Programs that target this category are being realized, but the experiences aren't being released; research institutions aren't interested about the subject; or yet: there aren't programs that work with teachers' illness within the public policies range. We conclude that further actions and policies are necessary to prevent the truth from being silenced. New studies about the health/illness processes and the lack of management may contribute to improve the situation.

Keywords: Workers' Health; Illness; Teacher; Health Management.

\section{Introdução}

O termo gestão/administração em saúde pode ser entendido como o "saber-fazer" no gerenciamento/manutenção do campo da saúde. É o conhecimento que se aplica no manejo das organizações de saúde, englobando a gerência de redes, as esferas públicas de saúde - como hospitais, laboratórios, clínicas e todas as outras instituições e serviços destinados à lida da saúde (Lorenzetti et al., 2014).

Especificamente sobre a rede de atenção à saúde, sua constituição fundamenta-se num complexo de unidades de diferentes perfis e funções, organizadas de forma articulada, e responsáveis pela manutenção e provimento integral de serviços de saúde à população de uma determinada região. O subsídio da construção de redes está na realidade de que, na maioria das populações, ocorrem casos que necessitam de atenção em serviços de menor complexidade do que naqueles de maior complexidade. Para que seja justificado seu investimento, faz-se imperativo um número suficiente de casos para que esse serviço não se torne ocioso. (Kuschnir; Chorny; Lira, 2012).

A Portaria $n^{0} 1.679$ (Brasil, 2002) prevê a estruturação da rede nacional de atenção integral à saúde do trabalhador no SUS (RENAST), desenvolvida por meio da articulação entre Ministério da Saúde, Secretarias de Saúde dos Estados, Distrito Federal e Municípios, sendo que, em seu artigo terceiro, define que, para a estruturação da RENAST, serão organizadas e implantadas: ações na rede de atenção básica e no Programa de Saúde da Família (PSF); rede de Centros de Referência em Saúde do Trabalhador (Cerest) e ações na rede assistencial de alta e média complexidade.

Os Cerest devem articular-se como polos irradiadores (em seu território de ação) em observância à cultura que perpassa a relação de trabalho, que pode culminar tanto em produção de saúde como em doença, tendo função de suporte técnico e científico da saúde do trabalhador. Deve atuar articulando-se também com toda a rede do SUS, de modo que os agravos decorrentes do trabalho sejam atendidos nos diferentes níveis de atenção do SUS.

Neves (2013), ao discorrer acerca da rede de atenção integral à saúde do trabalhador, analisa 
que entre a implantação dessa, no ano de 2002, e a publicação da política nacional de saúde do trabalhador, em 2012, a saúde do trabalhador (ST) modifica o eixo, no sentido de que, se, no início, os Cerest tinham caráter de assistência ambulatorial, a datar de 2005, com a Portaria 2.437, passa-se então a tomar a vigilância epidemiológica e sanitária como foco organizativo, por meio das definições vindas da Rede Sentinela e da atenção primária, e com a política nacional de saúde do trabalhador, devem assumir o apoio matricial ${ }^{2}$ de toda a Rede SUS, em especial à atenção primária e dela à Estratégia de Saúde da Família. Uma forma de identificar demandas que necessitam de ação é por meio do estudo epidemiológico local. No campo da ST, algumas condições, como agravos, doenças ou eventos, em consequência das condições de trabalho, são de notificação compulsória. Em 2014, a Portaria $n^{\circ} 1.271$ (Brasil, 2014a), juntamente com a Portaria n 1.984 (Brasil, 2014b) mantém como notificação compulsória os transtornos mentais decorrentes de atividade laboral, condensando as demais doenças em outras cinco proposições: câncer relacionado ao trabalho; dermatoses ocupacionais; lesões por esforços repetitivos/distúrbios osteomusculares relacionados ao trabalho (LER/ DORT); perda auditiva induzida por ruído (PAIR) relacionada ao trabalho e pneumoconioses relacionadas ao trabalho. Dentre as doenças/transtornos citados, alguns deles, como os transtornos mentais decorrentes de atividade laboral e as LER/DORT, são frequentemente relatados em estudos que investigam o adoecimento docente. Além destes, as questões relativas à saúde vocal também têm aparecido constantemente.

\section{Saúde docente: o mal-estar em professores de escolas públicas brasileiras.}

Segundo Esteve (1999), a expressão "mal-estar docente" já é usada desde meados dos anos de 1950, para descrever os efeitos negativos sofridos pelos professores, resultantes das condições psicológicas e sociais nas quais se tem dado a docência.

Tal expressão no campo da saúde docente tem sido empregada em ocasiões nas quais algo não vai bem, porém não se sabe explicar ao certo o que ocorre, nem por quais motivos. Como resultado, há aumento do absenteísmo, redução da qualidade pedagógica e, principalmente, sofrimento humano (Pereira, 2007).

Em pesquisa-intervenção realizada pelo Programa de Formação e Investigação sobre a Saúde e o Trabalho (PFIST) da Universidade Federal do Espírito Santo (Ufes), Barros e Louzada (2007) indicaram de modo perspicaz uma relação de dor e desprazer no trabalho docente. Observaram que a dor tem relação com a "precarização das relações de trabalho nas escolas, pelas formas instáveis de contratação (como a designação temporária - DT), pelo baixo investimento em formação e pelos fracos vínculos que os trabalhadores estabelecem nos e com seus espaços/processos de trabalho." (2007, p. 27). Um fator levantado como parte da realidade de adoecimento é a intensificação do trabalho docente. Assunção e Oliveira (2009) refletem que, na Lei de Diretrizes e Bases da educação (LDB), as atribuições dos professores não se restringem à sala de aula. Esse profissional também deve estar em constante relação com a comunidade (escolar e extramuros), participar da gestão da escola, do planejamento do projeto pedagógico, de conselhos, dentre outras tarefas. Afirmam também que a intensificação se dá pela cobrança crescente por produção, com a diminuição do efetivo sem haver mudança na produção, como ocorre com a dispensa de profissionais contratados.

Antunes (2014) discute sobre o mal-estar e o adoecimento docente nas escolas públicas do estado de São Paulo, destacando a atual situação das readaptações (por motivo de adoecimento), que se configura na recolocação do profissional em outra função, com atribuições de cargo em nível diferente (inferior) de esforço para o qual foi admitido. Em sua pesquisa, a autora levanta o número de professores

\footnotetext{
20 Apoio Matricial é uma proposta de articulação dos cuidados em saúde na Atenção Básica, constituindo um arranjo organizacional, por meio do qual profissionais especializados oferecem o suporte técnico para equipes responsáveis pelo desenvolvimento de ações básicas de saúde (Dimenstein et al., 2009).
} 
readaptados em São Paulo entre o ano de 2011 e o primeiro quadrimestre de 2013. Os resultados mostram que em 2011 havia 11.872 professores readaptados; no ano de 2012, 13.925; e em 2013, 14.268, demonstrando expressivo crescimento. Esta breve revisão de literatura apontou significativo adoecimento de docentes de escolas públicas brasileiras, parecendo ter direta relação com diversos fatores conjunturais. Perante tal realidade, buscou-se compreender se e como vem sendo feita a gestão das ações em saúde da categoria professor, que têm apresentado adoecimento em números significativos, observando que estes profissionais fazem parte de uma classe trabalhadora, logo, legalmente inclusos no rol de política referente à saúde do trabalhador. A realização deste estudo fundamentou-se em possíveis contribuições para a compreensão da gestão da saúde docente.

\section{O caminho metodológico}

Desenvolvemos aqui uma revisão integrativa da literatura dos últimos 25 anos (1990-2014), de acordo com o proposto por Botelho, Cunha e Macedo (2011). A base de dados definida foi a Biblioteca Virtual em Saúde (BVS-MS/Bireme), e os unitermos foram consultados na base de Descritores em Ciências da Saúde (DECS): 1) docente; 2) professor; 3) professor Ensino Fundamental e Médio; 4) saúde do trabalhador; 5) ambiente de trabalho; 6) serviços de saúde do trabalhador; 7) programas de assistência a saúde dos trabalhadores; 8) atenção à saúde do trabalhador; 9) licença médica; 10) condições de trabalho; 11) esgotamento profissional, 12) Educação Infantil. Os critérios de exclusão foram: estudos internacionais, professores de escolas particulares; professores universitários e de inclusão; tendo preferência por estudos realizados no Brasil, em língua portuguesa (artigos, teses e dissertações), realizados com professores de escolas públicas (educação infantil, ensino fundamental e médio), com a temática da docência, saúde e/ou adoecimento.

As informações obtidas nos estudos foram sumariadas, por meio de uma adaptação do instrumento validado por Ursi (2005), e categorizadas, analisadas e interpretadas à luz da saúde do trabalhador e da legislação vigente.

A primeira busca gerou o alcance de número muito reduzido de produções, nas bases de dados consultadas. Partimos, então, para uma segunda busca, na qual foi incluído um termo mais genérico encontrado no DECS3: "assistência à saúde", a ser combinado com um termo extra, que não consta de modo tão específico no DECS, "trabalhador". A mudança gerou um número de respostas mais amplo, porém ainda muito reduzido. Fizemos então uma terceira busca, com apenas três descritores (mais genéricos) encontrados no DECS: docente, professor e saúde do trabalhador. Além da análise qualitativa das publicações, alguns dados dos estudos, como local de realização, publicação, bases de dados, entre outros, foram digitados em planilhas eletrônicas com o intuito de gerar dados numéricos que colaborassem com as análises.

\section{As descobertas}

Das 242 produções encontradas na BVS, 52 foram pré-selecionadas e 190 excluídas por não estarem de acordo com os critérios de inclusão. Destas excluídas, quinze respondiam aos critérios gerais, contudo não estavam disponíveis para a consulta na íntegra, ou não disponíveis gratuitamente, e uma se tratava de áudio. Foram analisados 41 artigos, oito dissertações de mestrado e três teses de doutoramento.

As publicações começam a aparecer timidamente a partir do ano de 2002, não sendo encontrada nenhuma produção entre os anos de 1990 e 2001. Mais de $50 \%$ dos estudos foram publicados nos últimos quatro anos, demonstrando crescimento da visibilidade e preocupação da academia em torno do tema.

Quanto ao objetivo de investigação das publicações, observou-se que dezoito concentraram-se no estudo relacionado à docência e o aparecimento de problemas da voz; dez tiveram temas como: estresse, síndrome de burnout, depressão, transtornos

3 Descritores em Ciências da Saúde (DECS): Base de busca de descritores. (BVS, 2015) 
mentais comuns (TMC); nove focalizaram dor muscoesquelética/sintomatologia osteomuscular em; sete referem-se a estudos com relação ao trabalho/prazer/desprazer; quatro observam a qualidade de vida; duas traçam a relação entre gênero e adoecimento docente; uma era dedicada a saúde docente e movimento social/sindical, e uma tratava de saúde docente e estilo de vida. Pelo menos 70\% dos estudos estavam preocupados em discutir a questão de doenças específicas que vêm acometendo os professores.

Relacionado aos apontamentos sobre a gestão da saúde docente, dos 52 estudos, onze relatam algum tipo de ação/assistência docente. Apenas quatro concernem à assistência por meio da gestão em Saúde Pública e os demais (sete) referem-se a programas desenvolvidos por Instituições de Ensino Superior, destinados a professores de escolas públicas. Em geral, as ações não vinculadas diretamente ao SUS são de responsabilidade de universidades, em algumas experiências associadas aos sindicatos dos trabalhadores docentes. Por outro lado, as quatro únicas experiências apresentadas foram desenvolvidas por: Cerest Estadual (Tocantins); Secretaria de Administração Municipal (Rio de Janeiro); Hospital do Servidor Público Municipal (São Paulo); e um relato experiência de Santa Catarina, apresentado de forma superficial no estudo, não explicitando o órgão que a desenvolveu, nem características específicas da atividade citada.

$\mathrm{Na}$ Tabela 1 relaciona-se cada um desses quatro estudos que relatam ações desenvolvidas no SUS. As experiências encontradas acontecem na região Sudeste, Norte e Sul. Dois trabalhos têm como foco a saúde da voz; um realiza atividade física (ioga); e o outro trabalho, realizado por um Cerest (Tocantis), é um tanto mais amplo, envolvendo a reflexão do processo de trabalho e formas de enfrentar contextos adoecedores.

\section{Tabela I - Estudos com apontamentos de assistência ao docente no SUS}

\begin{tabular}{|c|c|c|c|c|c|}
\hline $\begin{array}{c}\text { Tipo de } \\
\text { publicação }\end{array}$ & $\begin{array}{l}\text { Local do } \\
\text { estudo }\end{array}$ & Autores & Ano & $\begin{array}{l}\text { Título do } \\
\text { estudo }\end{array}$ & Ação \\
\hline Dissertação & $\begin{array}{l}\text { Sudeste } \\
\text { Rio de } \\
\text { Janeiro- } \\
\text { RJ }\end{array}$ & Sptiz & 2009 & $\begin{array}{l}\text { Para não calar a voz dos nossos } \\
\text { professores: um estudo das } \\
\text { desordens vocais apresentadas } \\
\text { pelos professores da rede } \\
\text { pública municipal do Rio de } \\
\text { Janeiro. }\end{array}$ & $\begin{array}{l}\text { Programa de Saúde Vocal (PSV) } \\
\text { - Coordenadoria de Valorização } \\
\text { do Servidor da Coordenadoria } \\
\text { de Sistema de RH da Sec. Munic. } \\
\text { De Adm.; tem como finalidade } \\
\text { principal difundir os conhecimentos } \\
\text { relacionados à voz. }\end{array}$ \\
\hline Artigo & $\begin{array}{l}\text { Sul } \\
\text { Florianópolis } \\
\text { - SC }\end{array}$ & $\begin{array}{l}\text { Pereira, } \\
\text { Teixeira e } \\
\text { Lopes }\end{array}$ & 2013 & $\begin{array}{l}\text { Qualidade de vida de } \\
\text { professores de educação básica } \\
\text { do município de Florianópolis, } \\
\text { SC, Brasil. }\end{array}$ & $\begin{array}{l}\text { Programa de atividades físicas como } \\
\text { ioga e ginástica postural para os } \\
\text { professores municipais. }\end{array}$ \\
\hline Artigo & $\begin{array}{l}\text { Sudeste } \\
\text { São Paulo } \\
\text { - SP }\end{array}$ & $\begin{array}{l}\text { Karmanne } \\
\text { Lancman }\end{array}$ & 2013 & $\begin{array}{l}\text { Professor - intensificação do } \\
\text { trabalho e o uso da voz. }\end{array}$ & $\begin{array}{l}\text { Os professores do município de São } \\
\text { Paulo são atendidos, em grupo, pela } \\
\text { Seção de Fonoaudiologia do Hospital } \\
\text { do Servidor Público Municipal de } \\
\text { São Paulo. }\end{array}$ \\
\hline Dissertação & $\begin{array}{l}\text { Norte } \\
\text { Tocantins }\end{array}$ & Freire & 2014 & $\begin{array}{l}\text { As vivências de sofrimento de } \\
\text { docentes do Tocantins: pistas } \\
\text { para ações de Vigilância em } \\
\text { Saúde do Trabalhador }\end{array}$ & $\begin{array}{l}\text { Projeto Promoção da Saúde dos } \\
\text { Trabalhadores da Educação- } \\
\text { Cerest-To - Para professores de } \\
\text { escolas públicas estaduais. }\end{array}$ \\
\hline
\end{tabular}


Apesar de apenas quatro estudos apresentarem gestão da saúde/adoecimento docente via política pública, foram observadas algumas recomendações em grande parte dos estudos averiguados: doze indicam que mais estudos sejam realizados; outros doze recomendam que políticas públicas sejam planejadas e implantadas no que se refere à saúde do professor; oito sugerem a necessidade de mais estudos bem como políticas públicas; três indicam o desenvolvimento de medidas preventivas dentro da escola; e outros dois, o desenvolvimento de programas que aumentem a autonomia do professor. Em menor proporção (apenas um estudo para cada recomendação), foram encontradas as seguintes recomendações: estudo de formas de enfrentamento e não apenas adoecimento; modificação das políticas escolares; revisão da legislação trabalhista e aplicação da Norma da ABNT NR17 (que estabelece parâmetros que permitam a adaptação das condições de trabalho às características psicofisiológicas dos trabalhadores), como forma de prevenir danos aos professores; sugestão de um modelo de roteiro-guia para avaliação da condição de saúde dos professores; sugestão de realizar notificações quando do adoecimento docente; maior articulação entre o sistema educacional e o de saúde no caso de afastamentos ou readaptações, para que o professor não retorne ao mesmo ambiente/ contexto que o adoeceu. Do total de estudos, sete não tecem nenhum tipo de recomendação.

\section{Gestão em Saúde Pública quanto à saúde docente: das experiências encontradas à falta de articulação no campo.}

Os estudos citados na Tabela 1 apontam experiências desenvolvidas via saúde pública no que tange a saúde docente, entretanto apenas as autoras Sptiz (2009) e Freire (2014) detalham as atividades que prestam atendimento a docentes, sendo que, dessas, somente em Freire a experiência é voltada especificamente para a categoria docente.

0 primeiro relato refere-se a uma dissertação de mestrado em Ciências na área de Saúde Pública, desenvolvido por Spitz (2009). No estudo, a autora avalia diagnósticos, causas e critérios de readaptação funcional por problemas de voz de professores da rede pública municipal de ensino da cidade do Rio de Janeiro durante o ano de 2007. A autora relata o Programa de Saúde Vocal (PSV), pertencente ao departamento de Perícia Médica da Coordenadoria de Valorização do Servidor, vinculada à Coordenadoria de Sistema de Recursos Humanos da Secretaria Municipal de Administração. 0 estudo também contou com entrevistas aos componentes da Gerência de Perícias médicas (GPM), sendo divididos em três grupos: Grupo 1, Médicos Peritos da GPM, incluindo os assessores da gerência e o subgerente de readaptação; Grupo 2 Fonoaudiólogas do PSV que atuam na GPM; Grupo 3, gerente da GPM. O objetivo do PSV era ensinar sobre o uso profissional da voz e a conduta vocal no uso profissional da voz, tendo como principais atribuições:

Controlar o programa de saúde vocal elegível aos professores do Município do Rio de Janeiro; Visitar periodicamente e estudar detalhadamente os locais de trabalho e analisar sob que condições as pessoas exercem no mesmo a sua atividade; Subsidiar a Gestão de Saúde do Trabalhador promovendo ou realizando a avaliação da função vocal dos profissionais da voz, como parte integrante dos exames ocupacionais, com atenção especial para os sinais e sintomas relacionados ou que tenham influência no desempenho de sua atividade ocupacional; Integrar e participar do trabalho de equipe multidisciplinar e/ou multiprofissional que cuida dos problemas da saúde do trabalho; Estudar as condições de trabalho e avaliar os resultados das pesquisas com potencial de risco para a voz e a saúde do trabalhador; Realizar avaliação da função vocal nos exames admissionais e na concessão de benefícios nos profissionais da voz; Elaborar laudo pericial fonoaudiológico baseado em instrumentos de avaliação da função vocal; Fornecer ao Médico Perito subsídios técnicos sobre a avaliação da função vocal relacionada à concessão de benefícios, bem como nos exames admissionais; Orientar e encaminhar servidores para avaliação e/ou tratamento (Spitz, 2009, p. 161).

Conforme relatado por Spitz (2009), a equipe do PSV, além das atividades específicas de perícia, 
tratamento e readaptação, também integra atividades de equipe multidisciplinar e/ou multiprofissional responsável por pensar os problemas da saúde do trabalho, além de estudar as condições das atividades laborais e avaliar os resultados das pesquisas com potencial de risco para a voz e a saúde dos trabalhadores; contudo a experiência citada parece ter mais relação com a necessidade do capital em manter o trabalhador produtivo do que especificamente com a saúde do trabalhador. Primeiro, pelo local de onde vem: Secretaria de Administração. Segundo, por ser um trabalho restrito, no caso, relativo aos problemas de voz. Além disso, a autora aponta um distanciamento entre o PSV e a perícia nos resultados da entrevista que realizou com a equipe da gerência: os grupos 1 e 3 responderam com unanimidade que na GPM não há confecção de nexo causal para a patologia vocal apresentada pelos professores. E todos os grupos recomendaram compra e uso de microfone, sugerindo a adaptação do trabalhador ao ambiente e não o oposto (Spitz, 2009). Quanto à articulação no campo, no estudo citado, os três grupos de entrevistados afirmaram as dificuldades de reinserir o professor no mesmo ambiente de trabalho, uma vez que a GPM pertence à Secretaria Municipal de Administração e os professores pertencem à Secretaria Municipal de Educação e, como não há vínculo, a ação é limitada, ficando a cargo dos próprios professores a articulação de seu retorno com a Coordenadoria Regional de Educação em que está lotado.

A segunda experiência a ser relatada é narrada por Freire (2014) e se encontra em uma dissertação de Mestrado Profissional em Saúde Pública. No estudo, é analisado o "Projeto de Promoção da Saúde dos Trabalhadores da Educação", desenvolvido pelo Cerest-TO em conjunto com trabalhadores da educação. O programa foi criado no intuito de compreender e assim intervir nas condições de trabalho e saúde (mental) de professores de escolas públicas estaduais do estado de Tocantins. A autora relata que o Cerest-TO trabalha em quatro frentes: Projeto de Fortalecimento da Política Estadual de ST; Vigilância, Epidemiologia e Informação; Vigilância em Ambientes e Processos de Trabalho; e Implantação da assistência ao trabalhador na atenção primária. O início do trabalho com a categoria docente se deu em 2007, quando a equipe do Cerest foi procurada pela Secretaria de Estado da Educação, que solicitou a investigação dos afastamentos que vinham ocorrendo por comprometimento da saúde dos professores, pois os registros apontavam vários deles com diagnósticos de transtornos mentais (transtornos do humor, episódios depressivos, transtornos depressivos recorrentes, transtorno bipolar, episódio maníaco; transtorno afetivo bipolar; episódio depressivo; transtorno depressivo recorrente; transtornos persistentes do humor (afetivos); transtornos mentais e comportamentais decorrentes do uso de substâncias psicoativas; transtornos neuróticos relacionados com estresse e somatomorfes; fobias, pânico, ansiedade generalizada, transtorno obsessivo-compulsivo e hipocondria), LER/DORT e doenças cardiovasculares.

Observou-se que o programa citado foi construído de acordo com as necessidades da demanda; a autora afirma que, quando solicitada a intervenção, a equipe do Cerest aproximou-se do contexto de trabalho nas escolas para compreender o conjunto de determinações que influenciam o processo saúde-doença docente e assim propor as atividades. Para tal, foi constituída uma parceria entre a equipe técnica da Secretaria Estadual de Educação (SEDUC), que fez contato com a Junta Médica da Secretaria da Administração (responsável pela concessão de afastamentos dos funcionários por motivo de saúde no estado), a fim de levantar informações sobre os afastamentos. Depois, houve articulação com o Sindicato dos Trabalhadores da Educação (Sintet), pela Seduc e pelo Cerest, e por fim foi firmado um Termo de Cooperação Técnica ( $n^{0}$ 026/2009) entre as Secretarias de Educação e Cultura, Saúde e Administração e o Sintet.

Foram desenvolvidas oficinas de Promoção da Saúde dos Trabalhadores da Educação, reuniões, palestras e ações de vigilância (no formato de inspeções) e entrevistas. Esse projeto baseou-se no programa citado anteriormente: Programa de Formação em Saúde Gênero e Trabalho nas Escolas. (Freire, 2014).

Percebe-se que em relação ao último estudo citado, o percurso do programa foi construído 
e implementado de acordo com o que é preconizado pela portaria 1.823 (Brasil, 2012), na qual a implementação da Política Nacional de Saúde do Trabalhador e da Trabalhadora deverá levar em consideração a articulação entre ações individuais (assistência e recuperação dos agravos), com ações coletivas como a promoção, prevenção, vigilância de ambientes, processos e atividades de trabalho, intervenção sobre os fatores determinantes da saúde; ações de planejamento e avaliação com as práticas de saúde; além de priorizar o envolvimento do conhecimento técnico e os conhecimentos, experiências e subjetividade dos trabalhadores e suas práticas institucionais.

Comparando as duas experiências citadas, é possível observar como a falta de articulação no campo, como relatado no estudo de Sptiz (2009), dificulta o desenvolvimento integral de atividades voltadas para a saúde do trabalhador, além disso, o próprio setor (Secretaria de administração/ Perícias Médicas) no qual o programa se desenvolve bem como as características descritas no estudo denotam atuação mais voltada para a medicina do trabalho do que propriamente para a saúde do trabalhador, conforme já discutido. Por outro lado, o trabalho narrado por Freire (2014) explicita uma experiência análoga daquilo almejado pela política de saúde do trabalhador. Tais realidades estão ligadas de forma intrínseca à questão da "gestão".

0 arcabouço legislativo brasileiro referente à Saúde do Trabalhador possibilita o desenvolvimento das atividades como as supracitadas; para tanto é necessário lembrar que em geral os serviços de saúde possuem peculiaridades que exigem tratamento diferenciado no que se refere à organização e à gestão. Por exemplo, as necessidades atendidas são complexas e variáveis, englobando perspectivas biofísicas e psicossociais, tendo direta ligação com a questão da classe social e aquilo que se entende por conceito de saúde, doença, morte; clientela e do tipo de problema, seja ele agudo ou crônico. Existem ainda variações individuais; por isso, a gestão necessita de autonomia para adaptar os serviços ofertados às necessidades específicas trazidas por esses usuários. Em se tratando do serviço público, as organizações são dependentes do ambiente sociopolítico, uma vez que seu funcionamento tem regulação externa. Embora possam desenvolver esta autonomia, a prática da organização depende daquilo que é fixado por uma autoridade externa, como o governo, no caso (Dussault, 1992).

Onocko Campos e Campos (2006) afirmam que nos mais de cinco mil municípios brasileiros, apesar de haver regras gerais para regular o SUS, existe autonomia quase absoluta para cada gestor de saúde dirimir em função de quais princípios ou lógica organizará o sistema de saúde local. No entanto, os autores classificam essa autonomia como perversa, uma vez que não é possível sustentar um sistema de saúde que responda satisfatoriamente às necessidades apresentadas se não houver tomada de decisão (com subsídio concreto e político das esferas de governo) que contemple a elaboração de um projeto sólido e coerente, subsidiado em critérios técnicos e controle social. Assim, consideram a chamada coconstrução de autonomia como um dos fins do trabalho em saúde, cujas implicações são políticas, epistemológicas e organizacionais, de modo que é imprescindível a reformulação ampliada tanto dos valores políticos como do sistema de conceitos teóricos que orientam o trabalho em saúde. Destaca-se, de acordo com os autores, que a mudança protagonista deste cenário é a redefinição do objeto do trabalho em saúde, pensando a partir de então esse objeto como uma síntese de problemas de saúde (riscos, vulnerabilidade e enfermidade) sempre em relação a sujeitos concretos.

A valorização do sujeito e, por conseguinte, a valorização de sua singularidade altera radicalmente o campo de conhecimento e de práticas da saúde coletiva. Tal mudança protagonista significa desenvolver a gestão em saúde de forma política, que considere e contemple os setores, como a categoria dos trabalhadores. Uma vez que há silenciamento desses sujeitos, volta novamente a indagação: por que não falar sobre a questão de forma que o diálogo possibilite a implementação das políticas já existentes? A respeito de discursos silenciados, Mello (2008) afirma que, do mesmo modo que a palavra, o silêncio também é portador de um peso, e é, por vezes, alguma coisa envolvendo sentidos a serem descobertos. Para o autor, falar sobre o 
silêncio é uma forma de desvelá-lo, para compreender as diversas significações que nele subjaz.

Faz-se necessário aqui destacar que o silêncio ao qual nos referimos é aquele do mundo ocidental, no sentido de calar a voz. Compreende-se, então, que o silêncio "na" e "sobre" a gestão em saúde não é a simples negação da palavra; ele oculta a existência de fatos que, se tivessem visibilidade, demandariam muitas atitudes políticas para sua resolução, visto que o número de docentes na educação básica brasileira em 2013, segundo o censo escolar, já era de 2,1 milhões de professores (INEP, 2014), perfazendo considerável número de trabalhadores que podem desenvolver suas atividades em condições como aquelas descritas pelas pesquisas citadas, culminando em adoecimento.

Se as doenças que comumente vêm acometendo docentes fossem registradas no Sinan (Brasil, 2007), provavelmente ter-se-ia um patamar mais claro da frequência de adoecimento destes profissionais, uma vez que, ao detalhar os estudos apresentados nesta pesquisa, observa-se que as doenças mais comuns apresentadas por esta categoria estão contempladas na portaria $n^{\circ} 1.984$ (Brasil, 2014b), legislação mais atual que define a lista nacional de doenças e agravos de notificação compulsória, sendo que Transtornos mentais e Lesões por Esforços Repetitivos/Distúrbios Osteomusculares (LER/DORT) são amplamente encontrados como foco de estudos na população docente. Destaca-se que a portaria não contempla problemas de voz, apenas de audição. $\mathrm{O}$ adoecimento vocal foi o maior foco de estudos na bibliografia pesquisada.

Assim, conforme Campos (2010), é preciso construir outro paradigma para a gestão em saúde, reconhecendo e convivendo com a autonomia relativa dos trabalhadores, que desenvolva formas de controle sobre o trabalho segundo a perspectiva dos usuários, considerando o saber estruturado sobre saúde. $O$ autor lembra que para novos paradigmas é forçoso haver reformas organizacionais, sugerindo a adoção de sistema de cogestão e de apoio institucional, isto é, uma transformação que consubstancie modos de poder compartilhado entre gestor e equipe, entre clínico e equipe, entre profissionais e usuários.

\section{Considerações finais}

Diante de tais reflexões consideramos necessários novos estudos, que não silenciem a realidade tanto do processo saúde/adoecimento, como da falta de gestão acerca dele, bem como que discutam uma nova forma de gestão, que também quebre o silêncio diante das evidências do adoecimento docente e que, de fato, priorize ações em saúde do trabalhador e não retroceda à medicina do trabalho.

Em que pese se tenha encontrado produções sugerindo fortes evidências de adoecimento e poucas que apontam a gestão de saúde pública nesse campo, faz-se necessário destacar as limitações que permeiam este estudo. Por tratar-se de revisão bibliográfica, estruturou-se num recorte de tempo e espaço, portanto os resultados dizem respeito apenas ao universo pesquisado. Sendo a BVS uma base que agrega publicações em saúde, não estudamos as bases de dados específicas de trabalho e educação, onde, eventualmente, outros trabalhos poderiam estar presentes; além disso, a pesquisa ficou limitada a publicações em língua portuguesa, logo, estudos publicados em outras línguas não foram alcançados.

Pensamos ser possível que o número de estudos disponíveis seja maior do que o englobado neste trabalho. Destarte, os resultados não podem ser generalizados a princípio; todavia, por se tratar de estudo de produções no âmbito nacional, causa inquietações que nos permitem questionar a realidade da saúde/adoecimento docente no Brasil. Observando que o SUS possui ampla política destinada aos trabalhadores, e que os docentes fazem parte da classe trabalhadora, buscou-se compreender o que esse sistema tem feito frente a tal realidade.

De acordo com os resultados, é possível observar que, embora exista considerável número de publicações que versem sobre a questão da saúde, ou adoecimento docente, poucas relatam sobre a ação/ gestão da saúde pública em relação a essa população específica. Perante tal realidade, considerando o espaço de tempo e o local pesquisado, levantam-se três hipóteses. Primeira: os programas voltados para esta categoria estão sendo realizados, 
contudo os gestores não estão divulgando as experiências, portanto não existem publicações. Segunda: as instituições de pesquisa não têm se interessado pelo tema e. Terceira: realmente não existem programas que trabalhem com adoecimento docente no âmbito das políticas públicas.

Aqui, discutimos mais detalhadamente dois trabalhos, entretanto é importante que a discussão não se atenha apenas às experiências que aparecem, mas também ao discurso silenciado nos demais cinquenta trabalhos. Apesar de paradoxal, o silêncio pode nos sussurrar ideias, ou ao menos indagações, sendo importante levantar a discussão sobre os interesses envolvidos no falar ou no calar.

Neste sentido, novos estudos precisam ser realizados como forma de demonstrar a realidade de adoecimento da categoria, reforçando assim a necessidade de que políticas públicas contemplem a assistência à saúde das/os professoras/es. Do mesmo modo, faz-se imperativo que as redes de atenção, assim como preconizado pelo SUS, se atentem à questão, sendo importantes instrumentos os estudos epidemiológicos locais, que poderiam apontar o adoecimento coletivo, combatendo a ideia de que as morbidades nos docentes decorrem de questões individuais. De igual importância é a alimentação do Sinan, por meio das notificações e investigações de casos de doenças e/ou agravos, de acordo com a lista nacional de doenças que se enquadram como de notificação compulsória, destacando-se que é permitido aos estados e municípios agregar outros problemas de saúde que aparecem de modo considerável em sua região.

É importante destacar que apenas a gestão da saúde do professorado é insuficiente para resolver a questão. Uma vez que o contexto educacional se apresenta como espaço adoecedor, é essencial que seja reestruturado, pois cuidar da saúde do professor e recolocá-lo no mesmo espaço corresponde a uma atuação voltada para a medicina do trabalho (interesse do capital) e não para a integralidade do trabalhador (saúde do trabalhador). Portanto, é fundamental o entrelaçamento entre as políticas de saúde e de educação, sendo pertinente a participação das políticas de gênero, já que a população feminina é majoritária nesse campo. Tal conjunto de atividades poderia contribuir para o deslinde da realidade, um tanto obscura, do adoecimento docente, que progressivamente vem afetando os trabalhadores em educação.

\section{Referências}

ANTUNES, S. M. P. S. N. Mal-estar e adoecimento docente na escola pública paulista: um panorama preocupante. Convenit Internacional, Porto, $\mathrm{n}$. 15, 2014. Disponível em: <https://goo.gl/YB3Ze5>. Acesso em: 8 mar. 2015.

ASSUNÇÃO, A. A.; OLIVEIRA, D. A. Intensificação do trabalho e saúde dos professores. Educação e Sociedade, Campinas, v. 30, n. 107, p. 349-372, 2009. Disponível em: 〈https://goo.gl/uV4fT6>. Acesso em: 8 mar. 2015.

BARROS, M. E. B.; LOUZADA, A. P. Dor-desprazertrabalho docente: como desfazer essa tríade? Psicologia USP, São Paulo, v. 18, n. 4, p. 13-34, 2007. Disponível em: <https://goo.gl/oagSHa〉. Acesso em: 8 mar. 2015.

BVS - BIBLIOTECA VIRTUAL EM SAÚDE. Descritores em Ciências da Saúde (DECS). 2015. Disponível em: <https://goo.gl/wiardz>. Acesso em: 31 jan. 2016.

BOTELHO, L. L. R.; CUNHA, C. C. de A.; MACEDO, M. $O$ método da revisão integrativa nos estudos organizacionais. Revista Gestão e Sociedade, Belo Horizonte, v. 5, n. 11, p. 121-136, 2011. Disponível em: <https://goo.gl/1qzRmk>. Acesso em: 10 dez. 2014.

BRASIL. Portaria ${ }^{0} 1.679$ de 19 de setembro de 2002. Dispõe sobre a estruturação da rede nacional de atenção integral à saúde do trabalhador no SUS. Diário Oficial da União, Brasília, DF, 20 set. 2002. Disponível em: <https:// goo.gl/nhxH5d>. Acesso em: 22 nov. 2014.

BRASIL. Portaria $n^{0} 1.823$, de 23 de agosto de 2012. Institui a política nacional de saúde do trabalhador e da trabalhadora. Diário Oficial da União, Brasília, DF, 23 ago. 2012. Disponível em: <https://goo.gl/GhnBaZ>. Acesso em: 1 nov. 2014.

BRASIL. Ministério da Saúde. Secretaria de Vigilância em Saúde. Departamento de Vigilância Epidemiológica. Sistema de Informação de Agravos de Notificação - SINAN: normas e rotinas. 
Brasília: Editora do Ministério da Saúde, 2007. Disponível em: <https://goo.gl/wxMQgf>. Acesso em: 12 jan. 2015 .

BRASIL. Portaria ${ }^{0} 1.271$, de 6 de junho de 2014. Define a Lista Nacional de Notificação Compulsória de doenças, agravos e eventos de saúde pública nos serviços de saúde públicos e privados em todo o território nacional, nos termos do anexo, e dá outras providências. Diário Oficial da União. Brasília, DF, 6 jun. 2014a. Disponível em: <https:// goo.gl/c4aGmz>. Acesso em: 13 mar. 2015.

BRASIL. Portaria $\mathrm{n}^{0} 1.984$, de 12 de setembro de 2014. Define a lista nacional de doenças e agravos de notificação compulsória, na forma do Anexo, a serem monitorados por meio da estratégia de vigilância em unidades sentinelas e suas diretrizes. Diário Oficial da União, Brasília, DF, 15 set. 2014b. Disponível em: <https://goo. $\mathrm{gl} / 7 \mathrm{jcLVy}>$. Acesso em 13 mar. 2015.

CAMPOS, G. W. S. Cogestão e neoartesanato: elementos conceituais para repensar o trabalho em saúde combinando responsabilidade e autonomia. Ciência \& Saúde Coletiva, Rio de Janeiro, v. 15, n. 5 , p. 2337-2344, 2010. Disponível em: <https://goo.gl/ Mv8bdr>. Acesso em: 14 set. 2015.

DIMENSTEIN, M. et al. $\mathrm{O}$ apoio matricial em Unidades de Saúde da Família: experimentando inovações em saúde mental. Saúde e Sociedade, São Paulo, v. 18, n. 1, p. 63-74, 2009. Disponível em: <https://goo.gl/1JGJ4v>. Acesso em: 7 fev. 2016.

DUSSAULT, G. A gestão dos serviços públicos de saúde: características e exigências. Revista de Administração Pública, Rio de Janeiro, v. 26, n. 2, p. 8-19, 1992. Disponível em: <https://goo.gl/ guZRPJ>. Acesso em: 16 set. 2015.

ESTEVE, J. M. O mal-estar docente: a sala de aula e a saúde dos professores. Tradução Durley Carvalho Cavicchia. Bauru: Edusc, 1999.

FREIRE, L. S. M. As vivências de sofrimento de docentes do Tocantins: pistas para ações de vigilância em saúde do trabalhador. 2014. Dissertação (Mestrado Profissional em Saúde Pública) - Escola Nacional de Saúde Pública Sergio Arouca; Fiocruz, Rio de Janeiro, 2014.
Disponível em: <https://goo.gl/KWMsVP>. Acesso em: 8 maio 2015 .

INEP - INSTITUTO NACIONAL DE ESTUDOS E PESQUISAS EDUCACIONAIS ANÍSIO TEIXEIRA. Censo Escolar da Educação Básica 2013: resumo técnico. Brasília, DF: INEP, 2014. Disponível em: <https://goo.gl/ZwomXt>. Acesso em: 7 out. 2015.

KARMANN, D. F.; LANCMAN, S. Professor - intensificação do trabalho e o uso da voz. Audiology - Communication Research, São Paulo, v. 18, n. 3, 2013. Disponível em: <http://www.scielo. br/pdf/acr/v18n3/ao5v18n3.pdf>. Acesso em: 8 maio 2015.

KUSCHNIR, R. C.; CHORNY, A. H.; LIRA, A. M. L. Gestão dos sistemas e serviços de saúde. Florianópolis: Departamento de Ciências da Administração / UFSC, 2012.

LORENZETTI, J. et al. Gestão em saúde no Brasil: diálogo com gestores públicos e privados. Texto \& Contexto Enfermagem, Florianópolis, v. 23, n. 2, p. 417-425, 2014. Disponível em: <https://goo. gl/guLDzn>. Acesso em: 10 set. 2015.

MELLO, R. O silêncio faz sentido. In: MAGALHÃES, J. S. D.; TRAVAGLIA, L. C. (Org.) MÚLTIPLAS PERSPECTIVAS EM LINGÜÍSTICA. Coletânea de trabalhos apresentados no XI Simpósio Nacional de Letras e Linguística e I Simpósio Internacional de Letras e Linguística... Uberlândia, 2006. Uberlândia: Edufu, 2008. p. 2588-2594. Disponível em: <http://www.filologia.org.br/ileel/sumario. html $>$. Acesso em: 6 out. 2015 .

NEVES, I. R. De Centro de Reabilitação a Cerest: análise de um centro de referência regional em saúde do trabalhador no interior do Mato Grosso do Sul. 2013. Tese (Doutorado em Psicologia Social) - Pontifícia Universidade Católica de São Paulo, São Paulo, 2013.

ONOCKO CAMPOS, R. T.; CAMPOS, G. W. S. Coconstrução de autonomia: o sujeito em questão. In: CAMPOS, G. W. S. Tratado de Saúde Coletiva. São Paulo: Hucitec: Fiocruz, 2006.

PEREIRA, F. F. S. Indicadores de mal-estar docente em escolas públicas municipais de Salvador. 2007. Dissertação (Mestrado em Educação) - Faculdade 
de Educação da Universidade Federal da Bahia, Salvador, 2007. Disponível em: <https://goo.gl/ Gri4As>. Acesso em: 8 mar. 2015.

PEREIRA, E. F.; TEIXEIRA, C. S.; LOPES, A. S. Qualidade de vida de professores de educação básica do município de Florianópolis, SC, Brasil. Ciência \& Saúde Coletiva, Rio de Janeiro, v. 18, n. 7, 2013. Disponível em: <http://www.scielo.br/pdf/ csc/v18n7/11.pdf >. Acesso em: 2 maio 2015.

SPITZ, C. Para não calar a voz dos nossos professores: um estudo das desordens vocais apresentadas pelos professores da rede pública municipal do Rio de Janeiro. 2009. Dissertação (Mestrado em Ciências na área de Saúde Pública) - Escola Nacional de Saúde Pública Sergio Arouca; Fiocruz, Rio de Janeiro, 2009. Disponível em: <https://goo.gl/JEcDhn>. Acesso em: 8 jan. 2015.

URSI, E. S. Prevenções de lesões na pele no perioperatório: Revisão integrativa de literatura. 2005. Dissertação (Mestrado em Enfermagem) - Escola de Enfermagem da Universidade de São Paulo, Ribeirão Preto, 2005. Disponível em: <https://goo.gl/PcBNZT>. Acesso em: 26 nov. 2014.

\section{Contribuição dos autores}

Santana foi responsável pela elaboração da proposta, levantamento, análise e discussão dos dados e produção do artigo. Neves foi responsável pela orientação metodológica da pesquisa e revisão do manuscrito em todas as etapas de sua construção.

Recebido: 29/07/2016

Aprovado: 18/08/2017 